\title{
To what extent can clinical characteristics be used to distinguish encephalitis from encephalopathy of other causes? Results from a prospective observational study
}

Else Quist-Paulsen ${ }^{1,2^{*}}$ D, Anne-Marte Bakken Kran ${ }^{2,3,4}$, Elisabeth S. Lindland ${ }^{2,5,6}$, Katrine Ellefsen ${ }^{7}$, Leiv Sandvik ${ }^{8}$, Oona Dunlop ${ }^{9}$ and Vidar Ormaasen ${ }^{1}$

\begin{abstract}
Background: Recognizing patients with encephalitis may be challenging. The cardinal symptom, encephalopathy, has a wide array of differential diagnoses. In this prospective study we aimed to explore the etiology of encephalitis and to assess the diagnostic accuracy of symptoms and clinical findings in patients with encephalitis in an encephalopathic population.

Methods: Patients with acute onset of encephalopathy $(n=136)$ were prospectively enrolled from January 2014-December 2015 at Oslo University Hospital, Ullevaal. Clinical and biochemical characteristics of patients who met the case definition of encephalitis were compared to patients with encephalopathy of other causes.

Results: Among 136 patients with encephalopathy, 19 (14\%) met the case-definition of encephalitis. For 117 patients other causes of encephalopathy were found, infection outside the CNS was the most common differential diagnosis. Etiology of encephalitis was confirmed in 53\% (4 bacterial, 4 viral, 1 parasitic, and 1 autoimmune). Personality change, nausea, fever, focal neurology, recent travel history, and low inflammation markers were significantly more abundant in patients with encephalitis, but the diagnostic accuracy for individual parameters were low (area under the curve (AUC) <0.7). The combination of fever $(\mathrm{OR}=6.6,95 \%$ $\mathrm{Cl}, 1.6-28)$, nausea $(\mathrm{OR}=8.9,95 \% \mathrm{Cl}, 1.7-46)$ and a normal level of ESR (erythrocyte sedimentation rate $<17$ $\mathrm{mm} / \mathrm{hr}, \mathrm{OR}=6.9,95 \% \mathrm{Cl}, 1.5-33$ ) was significant in multivariate analysis with an AUC (area under the curve) of $0.85(95 \% \mathrm{Cl}, 0.76-0.94)$. Moderately increased pleocytosis in CSF $\left(5-100 \times 10^{6} / \mathrm{L}\right)$ further increased the diagnostic accuracy of this combination, AUC 0.90 ( $95 \%$ Cl, 0.81-0.98).

Conclusions: There is a wide diversity in differential diagnoses in patients with encephalopathy, and no single symptom or finding can be used to predict encephalitis with high accuracy in this group. The combination of fever, nausea and a low ESR in an encephalopathic population, increased the diagnostic accuracy of encephalitis compared to solitary parameters. The triad could be a useful clinical tool for early diagnosis of encephalitis, and these patients should be considered for further diagnostics such as lumbar puncture (LP).
\end{abstract}

Keywords: Infectious encephalitis, Encephalopathy, Diagnostic accuracy, Lumbar puncture, Central nervous system

\footnotetext{
* Correspondence: elpa1@ous-hf.no

'Department of Infectious Diseases, Oslo University Hospital Ullevaal, P. O.

Box 4956, Nydalen, N-0450 Oslo, Norway

${ }^{2}$ Institute of Clinical Medicine, University of Oslo, P.O Box 1171, Blindern,

0318 Oslo, Norway

Full list of author information is available at the end of the article
}

(c) The Author(s). 2019 Open Access This article is distributed under the terms of the Creative Commons Attribution 4.0 International License (http://creativecommons.org/licenses/by/4.0/), which permits unrestricted use, distribution, and reproduction in any medium, provided you give appropriate credit to the original author(s) and the source, provide a link to the Creative Commons license, and indicate if changes were made. The Creative Commons Public Domain Dedication waiver (http://creativecommons.org/publicdomain/zero/1.0/) applies to the data made available in this article, unless otherwise stated. 


\section{Background}

Recognizing patients with infection in the central nervous system (CNS) is both challenging and important. Procedures to obtain prompt diagnosis and to initiate treatment of acute bacterial meningitis (ABM) are well established in most hospitals. In contrast, infectious or immune mediated encephalitis is a much less investigated condition. Alteration in mental function (encephalopathy) is the cardinal symptom of encephalitis. Encephalopathy has a wide range of causes, and encompasses several serious conditions in need of immediate evaluation and treatment, including encephalitis [1-3]. Herpes simplex virus 1 (HSV1) is considered the most common cause of sporadic encephalitis [3-7]. Early initiation of treatment with acyclovir has been shown to substantially reduce mortality and morbidity [8-12]. Other causes of encephalitis, such as Mycobacterium tuberculosis or immune-mediated encephalitis also benefit from early initiation of treatment [5, 13-17]. However, despite extensive testing, the etiology of encephalitis often remains unknown $[4,7,13,18-20]$. In a retrospective study at our hospital, causative agent was confirmed in $42 \%$ of patients with encephalitis between 2000 and 2009 [21].

Identifying the encephalitic patient is the first vital step to initiate diagnostic algorithms and start empirical treatment. A lumbar puncture (LP) is mandatory, both to support the diagnosis and to ensure cerebrospinal fluid (CSF) for further analyses. Patients with encephalitis may present with subtle symptoms without typical symptoms of meningism. This may lead to delay in LP for patients suffering from encephalitis.

In this prospective study we wanted to explore the etiology and initial clinical presentation of patients with presumed infectious or autoimmune acute encephalitis. Secondly, we wanted to investigate whether clinical presentation or typical biochemical characteristics could be used to discriminate patients with encephalitis from patients with encephalopathy of other causes. Finally, we aimed to explore whether revised guidelines in the hospital have resulted in a higher identification rate of causative agents of encephalitis.

\section{Methods}

Oslo University Hospital (OUS) is a local hospital for parts of the city of Oslo and regional hospital for 2,7 million people. Each year approximately 24,000 patients are admitted to the emergency room (ER). Adult patients admitted between January 2014 and December 2015 were eligible for this study, focusing on patients with encephalopathy. To be sure that no patient with encephalopathy was missed, we prospectively included all patients that (1) had onset of or worsening of central nervous system (CNS) symptoms within less than seven days, and (2) were examined by a LP. Thus, patients presenting with any symptom of meningism or mental change such as altered consciousness, changed personality, new onset epilepsy, new onset headache in combination with fever and focal neurological signs were eligible for inclusion.

Patients who did not fulfill the inclusion criteria of encephalopathy were excluded from further analyses (Fig. 1).

Encephalopathy was defined as a change in mental function according to the set of clinical criteria described in Table 1. The assessment of change in mental status was based on the story of the patient, family and/or treating physician.

Patients with encephalopathy were divided into two groups for comparisons: Group A (fulfilling the criteria of encephalitis), and group B (encephalopathy of other cause). The case definition of encephalitis (Table 1) was based on the same criteria and symptoms as stated in the International Encephalitis Consortium case definition [22] . Etiological agents for patients with encephalitis were classified using the criteria given in the review of Granerod et al. [14].

All patients were evaluated by neurologist or internist, and by the investigators within 0-2 days. Encephalopathy had to be present for at least $24 \mathrm{~h}$ to fulfill the main criteria of encephalitis. For all patients, prior medical history, travel history, symptoms and clinical findings on the day of the LP were recorded. Fever was defined as either $\geq 38^{\circ} \mathrm{C}$ upon admission or within $24 \mathrm{~h}$ after admission, or measured to $\geq 38^{\circ} \mathrm{C}$ by patient prior to admission. A feeling of fever without documentation of such, was not defined as fever due to the uncertainty/unreliability of this symptom.

Patients were regarded as immunocompromised if they were under treatment for or had been treated for cancer within the last year (including hematological malignancies), if they were diagnosed with HIV infection or diabetes mellitus type 2 (DM2) or if they were taking immunosuppressive or immune modulating drugs. Initial blood tests, findings from the LP, CT and/or MRI and/or EEG, and data on antimicrobial treatment as well as diagnosis at discharge were collected from the hospital records.

By including a patient in the study, the clinician could apply premade study packages consisting of a standard set of CSF analyses and serological screening for selected agents (see Additional file 1). All CSF samples were analyzed with in house real time polymerase chain reactions (PCR) for detection of herpes simplex virus 1 (HSV1) and 2 (HSV2), varicella zoster virus (VZV) and enterovirus. Microscopy and culturing for bacteria were performed according to routine procedures, and PCR analyses for common bacterial causes of meningitis were 


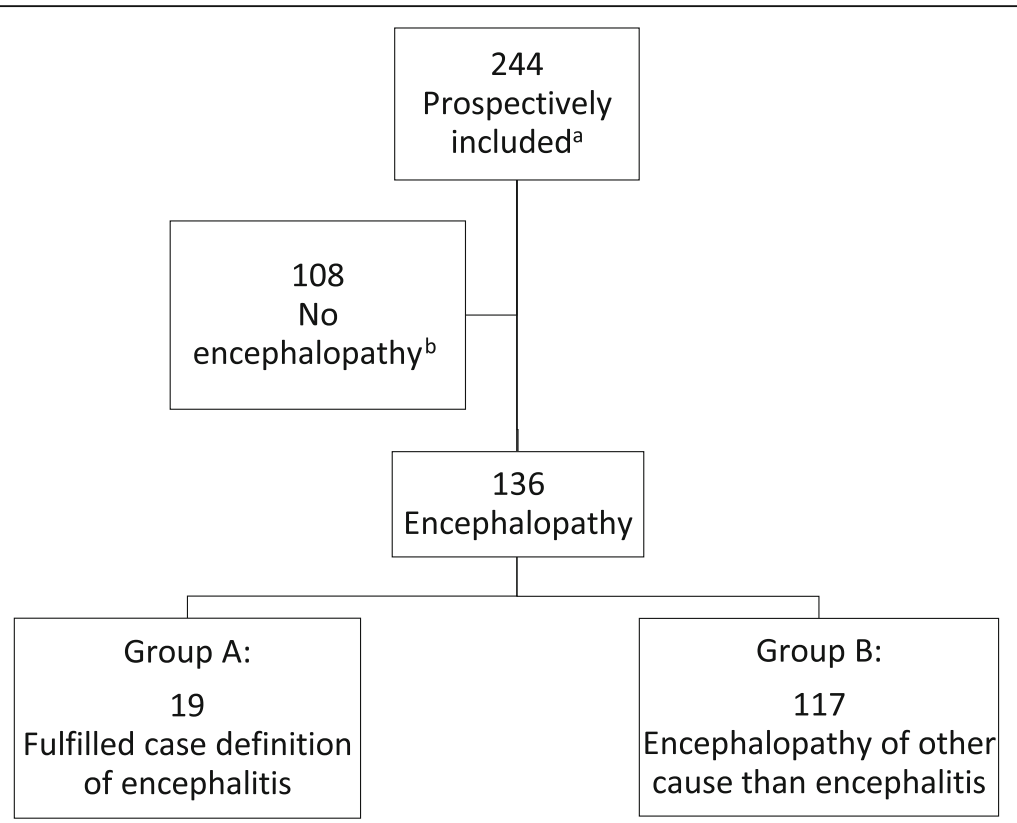

Fig. 1 Inclusion of patients and study groups; Legend: a 272 patients met the inclusion criteria; for 28 patients no informed consent was obtained. b 108 patients in whom no encephalopathy was found were excluded from present study

performed for patients treated with antibiotics prior to LP. Analyses for detection of other microbiological agents were performed if clinically relevant. Antibodies in serum and CSF were measured using serological assays in accordance with hospital recommendations. Biochemical analyses of blood and CSF were performed as part of the routine diagnostics using Sysmex XE-2100 (in 2014) and Sysmex XN-9000 (in 2015).

\section{Ethics and consent}

All patients or next of kin were asked for informed consent before or shortly after inclusion. The study protocol was reviewed and approved by the The Regional Committees for Medical and Health Research Ethics (REC South East, reference number 2011/2578) and the ethical council of the hospital.

\section{Statistical methods}

Patients fulfilling the case definition of encephalitis (group A) were compared to patients with encephalopathy of other causes (group B). Association between outcome variable and categorical data such as gender, immunosuppression, travel history and the presence of clinical symptoms were analyzed using Chi square test. Continuous data (e.g. age, blood pressure, heart rate, respiratory frequency and laboratory findings) were analyzed with Student $t$ test for normally distributed data, otherwise Mann Whitney $\mathrm{U}$ test was used. Results are presented as mean $( \pm \mathrm{SD})$ or median (interquartile range, IQR). Clinical symptoms and initial blood findings were combined in logistic regression analysis with encephalitis as dependent variable. Variables with more than $30 \%$ missing observations, e.g. D-dimer, were not analyzed as possible predictors for encephalitis. To measure how well a finding or model

Table 1 Case definitions

\begin{tabular}{|c|c|}
\hline Encephalopathy & $\begin{array}{l}\text { Decreased/altered consciousness } \\
\text { (unconsciousness, the patient is hard to keep awake or extensively tiredness) } \\
\text { and/or } \\
\text { change in cognitive function } \\
\text { (bewilderment, disorientation, latency, reduced ability to recall history or data) } \\
\text { and/or personality change } \\
\text { (aggression, new onset feeling of despair, inadequate/ strange behavior) }\end{array}$ \\
\hline Encephalitis & $\begin{array}{l}\text { Encephalopathy (=major criterion) for more than }>24 \text { hrs, with no other cause } \\
\text { identified and at least } 2 \text { of the following: } \\
\text { Objective fever }\left(\geq 38^{\circ} \mathrm{C}\right) \\
\text { CSF WBC count } \geq 5 \times 10^{6} / \mathrm{L} \\
\text { New onset seizures } \\
\text { New onset of focal neurological findings } \\
\text { CT/ MR findings consistent with encephalitis } \\
\text { EEG findings consistent with encephalitis }\end{array}$ \\
\hline
\end{tabular}


distinguishes between encephalopathy and encephalitis, the area under the ROC (receiver operating characteristic) curve (AUC) was calculated. The combination with the highest AUC was chosen as the final prediction model of encephalitis. In this final model, all parameters were significant when adjusting for each other.

Blood parameters were dichotomized to above or below reference levels of the hospital. For CSF findings, we found it neither relevant, nor safe to define a cutoff value for CSF parameters as the control group (group B) consists of cases with meningitis. Thus, for pleocytosis in CSF, intervals rather than absolute values were analyzed.

Statistical significance was defined as $p<0.05$. Data were analyzed using IBM SPSS Statistics 24.

\section{Results}

\section{Patient population}

Two hundred seventy-two patients met the inclusion criteria for assessment of having encephalopathy. However 28 patients were not enrolled in the study as we were not able to obtain informed consent. For 108 patients no sign of encephalopathy was found and these were excluded from the study. 136 patients were considered to have symptoms of encephalopathy, of these 19 (14\%) met the case definition of encephalitis (group A) as they fulfilled at least two minor criteria of the case definition, and no other cause of encephalopathy was identified. The diagnoses of patients in group $\mathrm{B}$ are shown in Table 2.

The most common condition was other infection, which was found in 58/117 (50\%). Bacterial meningitis was confirmed in 11 patients by detection of bacterial agent by bacterial growth or PCR in CSF and/or blood culture findings.

The mean age $( \pm$ SD) of the study population was 56.2 $( \pm 21)$ years. $47 \%$ were male. $15 / 136$ patients were transferred to our center from other hospitals, 3 patients were transferred from the department of psychiatry.

\section{Etiology}

Etiology was confirmed in 10/19 (53\%) of patients with encephalitis. The cause of encephalitis in relation to number of minor criteria in the case definition is shown in Table 3. In 9 patients (50\%), an infectious agent was confirmed (four bacterial, four viral, and one amoebic). Two patients had growth of Mycobacterium tuberculosis in the CSF, both presented without symptoms typical of meningitis. One of these had dual infection of TB and Cryptococcus neoformans. Specific IgG antibody response of Borrelia burgdorferi with elevated CSF/serum-index was found in two patients. None of these patients had headache or neck stiffness. The patient with Naegleria fowleri returned from holiday abroad on the day of admission and
Table 2 Diagnoses in patients with encephalopathy of other cause than encephalitis ( $n=117$, group B)

\begin{tabular}{|c|c|}
\hline Diagnostic category & No of patients \\
\hline \multicolumn{2}{|l|}{ Infection outside CNS ( $n=39$ ) } \\
\hline Respiratory tract & 21 \\
\hline Urinary tract & 3 \\
\hline Unknown/ other & 15 \\
\hline \multicolumn{2}{|l|}{ Infection in CNS $(n=19)^{a}$} \\
\hline Bacterial meningitis ${ }^{b}$ & 11 \\
\hline Aseptic meningitis ${ }^{c}$ & 5 \\
\hline Other CNS infections $^{\mathrm{d}}$ & 3 \\
\hline \multicolumn{2}{|l|}{ Neurological disease $(n=24)$} \\
\hline Epilepsy & 13 \\
\hline Nonepileptic seizures & 4 \\
\hline Other ${ }^{e}$ & 7 \\
\hline \multicolumn{2}{|l|}{ Encephalopathies $(n=8)^{f}$} \\
\hline Toxic & 4 \\
\hline Metabolic & 4 \\
\hline \multicolumn{2}{|l|}{ Other diagnosis $(n=27)$} \\
\hline Cerebrovascular disorders $^{9}$ & 6 \\
\hline Psychiatric disorders $^{\mathrm{h}}$ & 4 \\
\hline Unspecified disorientation and/ or coma & 4 \\
\hline Malignancy in CNS & 3 \\
\hline Pulmonary embolism & 3 \\
\hline Other ${ }^{j}$ & 7 \\
\hline
\end{tabular}

${ }^{a}$ Other than patients with encephalitis. ${ }^{b}$ S.pneumonia (6), S.aureus (3), $\mathrm{N}$ meningitides (1), K.oxytoca (1). ${ }^{c}$ Culture negative meningitis. ${ }^{d}$ Neurosyfilis, possible H1N1 encephalopathy, intracerebral abcess. ${ }^{e}$ Transient global amnesia (4), headache/migraine (3). ${ }^{\mathrm{f}}$ Alcohol withdrawal (2), drug intoxication (2), hepatic encephalopathy (2), hyponatriema (2). ${ }^{9}$ Cerebral vasculitis (1), sinuous venous thrombosis (1), cerebrovascular accident (4). ${ }^{\mathrm{h}}$ Depression (1), psychosis (2), unspecified delirium (1). ${ }^{i}$ Oligoastrocytoma (2), unknown (1). ${ }^{j}$ Dementia with other conditions (2), inflammatory disease (2, Morbus Adult still and Hemophagocytic lymphohistocytosis), medication side effect (1), vestibularis neuritis (1), arrhythmia (1)

etiology was confirmed by sequencing of material from autopsy. One patient was diagnosed with autoimmune encephalitis with N-methyl-D-aspartate (NMDA) receptor antibodies in CSF. Another three study patients were suspected of having autoimmune encephalitis; two of these were treated with steroids and immunoglobulins.

Clinical characteristics of encephalitis (group a) compared to patients with encephalopathy of other cause (group B) There were no statistical differences in age, gender, immunosuppression or duration of illness before admission, but patients with encephalitis reported more travel activity within the last 6 months (Table 4) compared with patients with encephalopathy of other cause.

Of the symptoms included in the major criterion of the case definition, a change in personality was significantly more abundant in patients with encephalitis 
Table 3 Etiology and number of minor criteria for patients diagnosed with encephalitis

\begin{tabular}{|c|c|c|}
\hline Number of minor criteria & Etiology $^{a}$ & No of patients \\
\hline \multirow[t]{5}{*}{2 minor criteria } & Varicella zoster virus (VZV) ${ }^{\mathrm{b}}$ & 2 \\
\hline & Adenovirus (ADV) & 1 \\
\hline & Borrelia burgdorferi ${ }^{\mathrm{C}}$ & 1 \\
\hline & Naegleria fowleri & 1 \\
\hline & Unknown & 2 \\
\hline \multirow[t]{5}{*}{$\geq 3$ minor criteria } & Herpes simplex type $1^{\mathrm{b}}$ & 1 \\
\hline & Mycobacterium tuberculosis ${ }^{d, f}$ & 2 \\
\hline & Borrelia burgdorferi $^{c}$ & 1 \\
\hline & NMDAr & 1 \\
\hline & Unknown & 7 \\
\hline
\end{tabular}

agent confirmed by either by ${ }^{\mathrm{b}} \mathrm{PCR}$ in $\mathrm{CSF}^{\mathrm{c}}{ }^{\mathrm{c}}$ intrathecal antibodyproduction or ${ }^{\mathrm{d}}$ positive culture of $M$ tuberculosis in CSF, ${ }^{\mathrm{e}}$ autopsy, sequencing of Naegleria fowleri. ${ }^{f}$ One patient had dual infection with Cryptococcus neoformans compared to those with encephalopathy of other cause. The level of consciousness and Glasgow coma score (GCS) on the day of the LP was similar in both groups. Fever was present in 14/19 (74\%) of patients with encephalitis, while only 55/117 (47\%) of those with encephalopathy of other cause had fever. Focal neurologic deficit such as hemiparesis, aphasia and cranial nerve palsies were present in 9/18 of patients with encephalitis. Patients with encephalitis reported nausea more often than the comparison group.

\section{Biochemical findings}

Biochemical laboratory results for group A and group B were compared, results are presented in Table 5. Median erythrocyte sedimentation rate (ESR), mean blood leucocyte count, mean neutrophil count and median D- dimer were significantly lower for patients with encephalitis.

Median CSF WBC count and protein concentration was higher for patients with encephalitis. Differential

Table 4 Clinical symptoms and findings of patients with encephalitis compared to patients with encephalopathy of other cause

\begin{tabular}{|c|c|c|c|}
\hline Characteristics $^{\mathrm{a}}$ & Encephalitis (group A) & Encephalopathy (group B) & $p$-value \\
\hline Age, years & $49( \pm 21)$ & $57( \pm 21)$ & 0.119 \\
\hline Gender, male & $6 / 19(32)$ & $58 / 117(50)$ & 0.145 \\
\hline Duration of hospital stay, days & $20(10-37)$ & $8(4-17))$ & 0.001 \\
\hline ICU & 10/19 (53) & $81 / 117(69)$ & 0.154 \\
\hline Death during hospitalization & $3 / 19(16)$ & 10/117 (9) & 0.326 \\
\hline No of patients with CNS symptoms $<24$ hrs & $8 / 17(47)$ & $68 / 101(67)$ & 0.106 \\
\hline Immunodeficiency & $4 / 19(21)$ & $28 / 117(24)$ & 0.784 \\
\hline Prodromal sickness ${ }^{c}$ & $14 / 19(74)$ & $75 / 109(69)$ & 0.670 \\
\hline Travel within 6 months & $8 / 18(44)$ & $17 / 100(17)$ & 0.009 \\
\hline Headache & $12 / 19(63)$ & $41 / 90(46)$ & 0.163 \\
\hline Photophobia & $6 / 17(35)$ & $16 / 70(23)$ & 0.290 \\
\hline Nausea & $13 / 16(81)$ & $35 / 81(43)$ & 0.005 \\
\hline Personality change ${ }^{d}$ & $9 / 19(47)$ & $25 / 105(24)$ & 0.034 \\
\hline Confusion $^{d}$ & 15/19 (79) & $62 / 106(59)$ & 0.091 \\
\hline Seizures $^{d}$ & $5 / 18(28)$ & $29 / 105(28)$ & 0.989 \\
\hline Fever & $14 / 19(74)$ & $55 / 117(47)$ & 0.031 \\
\hline Focal neurology & $9 / 18(50)$ & $23 / 99(23)$ & 0.019 \\
\hline $\mathrm{GCS}^{\mathrm{e}}$ & $14(12-14)$ & $13(10-14)$ & 0.219 \\
\hline GCS $\leq 14$ & 16/18 (89) & $90 / 114(79)$ & 0.324 \\
\hline $\mathrm{GCS} \leq 8$ & $1 / 18(6)$ & $27 / 114(24)$ & 0.080 \\
\hline Systolic blood pressure $(\mathrm{mmHg})$ & $140( \pm 28)$ & $132( \pm 28)$ & 0.275 \\
\hline Respiratory rate (/min) & $19( \pm 6)$ & $21( \pm 7)$ & 0.112 \\
\hline MRI findings suggesting encephalitis & $8 / 17(47)$ & $1 / 63(2)$ & $<0.001$ \\
\hline EEG findings indicative of encephalitis & $11 / 15(73)$ & $3 / 61(3)$ & $<0.001$ \\
\hline
\end{tabular}

${ }^{a}$ Data are presented as $\mathrm{n} / \mathrm{N}(\%)$, median (IQR) or mean $( \pm \mathrm{SD})$. Significant differences in bold. ${ }^{\mathrm{b}}$ Patient's description on how long they had been suffering from CNS symptoms before admission. ' Prodromal sickness: symptoms before onset of CNS symptoms. ${ }^{d}$ Observed/described either by patients, relatives or treating physician. ${ }^{e}$ GCS at the day of LP, for 17 patients who were intubated before LP the GCS closest to intubation is registered, 4 patients had their $\mathrm{LP}>24 \mathrm{~h}$ after intubation (=missing data). Also tested but not found to be relevant or not statistically significant: alcohol use, smoking habits, neck stiffness, illness among close relatives, vomiting, diastolic blood pressure, heart rate 
Table 5 Comparison of laboratory parameters of encephalitis versus encephalopathy of other cause

\begin{tabular}{|c|c|c|c|}
\hline Analysis & Encephalitis (group A) & Encephalopathy (group B) & $p$-value \\
\hline \multicolumn{4}{|l|}{ Blood results $^{a}$} \\
\hline Leucocyte count $\left(\times 10^{9} / \mathrm{L}\right)$ & $9.1( \pm 4.0)$ & $12.1( \pm 6.8)$ & 0.01 \\
\hline - Leucocytes $<10 \times 10^{9} / \mathrm{L}^{\mathrm{b}}$ & $13 / 19(68)$ & $50 / 117(43)$ & 0.037 \\
\hline Neutrophil count $\left(\times 10^{9} / \mathrm{L}\right)$ & $6.8( \pm 3.8)$ & $10.4( \pm 6.6)$ & 0.002 \\
\hline - Neutrophil $<7.3 \times 10^{9} / \mathrm{L}^{\mathrm{b}}$ & $12 / 19(63)$ & $34 / 98$ (35) & 0.020 \\
\hline ESR $(\mathrm{mm} / \mathrm{hr})$ & $12.5(3.0-26)$ & $22.5(9-46)$ & 0.015 \\
\hline$-E S R<17 \mathrm{~mm} / \mathrm{hr}^{\mathrm{b}}$ & $13 / 18(72)$ & $41 / 100(41)$ & 0.014 \\
\hline CRP (mg/L) & $6.3(0.9-53)$ & $32.0(2.5-118.0)$ & 0.09 \\
\hline D-dimer ( $\mu \mathrm{g} / \mathrm{L}, \mathrm{FEU})$ & $0.6(0.4-1.4)$ & $1.9(0.7-4.0)$ & 0.007 \\
\hline \multicolumn{4}{|l|}{ CSF results ${ }^{a}$} \\
\hline Leucocytes $\left(\times 10^{6} / \mathrm{L}\right)$ & $80(22-153)$ & $2(1-5.5)$ & $<0.001$ \\
\hline - CSF WBC 5-100 ( $\left.\times 10^{6} / \mathrm{L}\right)$ & $11 / 19(58)$ & 20/117 (17) & $<0.001$ \\
\hline Protein (g/L) & $0.87(0.45-1.1)$ & $0.39(0.30-0.59)$ & 0.001 \\
\hline - CSF protein $>0.45(\mathrm{~g} / \mathrm{L})^{\mathrm{c}}$ & 15/19 (79) & 44/116 (38) & 0.001 \\
\hline Glucose (mmol/L) & $3.2( \pm 1.2)$ & $4.1( \pm 1.8)$ & 0.023 \\
\hline - CSF: blood glucose & $0.5( \pm 0.2)$ & $0.6( \pm 0.2)$ & 0.071 \\
\hline Albumin (mg/L) & $566(295-747)$ & $231(147-345)$ & 0.005 \\
\hline - CSF: blood albumin & $13.6(7.0-18)$ & $6.3(3.5-9.8)$ & 0.006 \\
\hline
\end{tabular}

${ }^{a}$ data are median (IQR), mean $( \pm \mathrm{SD})$ or $\mathrm{n} / \mathrm{N}(\%) .{ }^{\mathrm{b}}$ No of patients with value below hospital reference level. ${ }^{\mathrm{c}}$ No of patients with value above hospital reference level. Analyzed, but not found relevant or significant; $\mathrm{Hb}$, thrombocytes, monocytes, eosinophils, lymphocytes, sodium, potassium, creatinine, lactate dehydrogenase, ASAT, ALAT, INR, CK, total protein, albumin, and CSF opening pressure

count in CSF revealed polymorphonuclear (PMN) dominance in $2 / 19(11 \%)$ patients with encephalitis, 12 patients from group B had PMN dominance $>70 \%$, including all patients being categorized as bacterial meningitis.

\section{Predictors of encephalitis}

Although some parameters differed significantly in patients with encephalitis compared with those with encephalopathy of other cause, no single symptom or finding showed good ability to predict the diagnosis of encephalitis (Table 6). ROC curves for selected single parameters are shown in Additional file 2.
The best predictor among the blood parameters was ESR $<17 \mathrm{~mm} / \mathrm{hr}$ with AUC level of $0.66(95 \% \mathrm{CI}$, 0.52-0.79). In CSF, WBC between 5 and $100 \times 10^{6} / \mathrm{L}$ had an AUC of 0.70 (95\% CI, 0.57-0.84). We wanted to assess whether combinations of symptoms or initial blood results could better predict the diagnosis of encephalitis. In regression analysis the combination of low ESR, fever and nausea had the highest AUC in this study (AUC 0.85 (95\% CI, 0.76-0.94), Fig. 2). When choosing an optimal cutoff, this prediction model has a sensitivity and specificity of 80 and $67 \%$ respectively.

When entering a moderate increase in CSF WBC (5$100 \times 10^{6} / \mathrm{L}$ ) to the above mentioned model, the AUC

Table 6 Comparisons between encephalitis (group A) and encephalopathy (group B)

\begin{tabular}{|c|c|c|c|c|}
\hline Symptom/ finding & AUC & Univariate OR (95\% Cl) & $p$-value & Multivariate analysis ( $p, 95 \% \mathrm{Cl}$ ) \\
\hline Nausea & 0.69 & $5.7(1.5-22)$ & 0.010 & $8.9(p 0.010,1.7-46)$ \\
\hline Focal finding & 0.63 & $3.3(1.1-9.3)$ & 0.024 & \\
\hline Fever & 0.63 & $3.2(1.1-9.3)$ & 0.038 & $6.6(p 0.011,1.6-28)$ \\
\hline Travel last 6 months & 0.64 & $3.9(1.3-11)$ & 0.012 & \\
\hline $\mathrm{ESR}<17 \mathrm{~mm} / \mathrm{hr}^{\mathrm{a}}$ & 0.66 & $3.7(1.2-11)$ & 0.019 & $6.9(p 0.014,1.5-32)$ \\
\hline Blood leucocytes $<10 \times 10^{9} / \mathrm{L}^{a}$ & 0.63 & $2.9(1.0-8.2)$ & 0.043 & \\
\hline Blood neutrophils $<7.3 \times 10^{9} / \mathrm{L}^{\mathrm{a}}$ & 0.64 & $3.2(1.1-9.0)$ & 0.024 & \\
\hline
\end{tabular}

${ }^{\mathrm{a}}$ Hospital reference levels as described in methods 


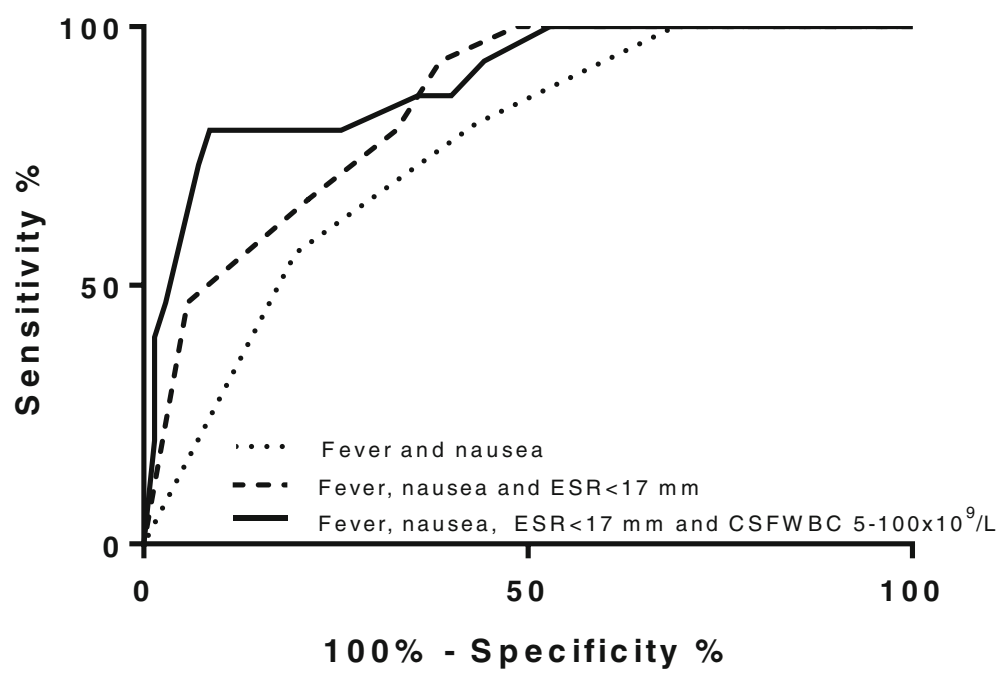

Fig. 2 ROC curves for combination of clinical characteristics for the diagnosis of encephalitis in an encephalopathic population; Legend: Figure showing ROC curves of the model with the highest diagnostic accuracy of predicting encephalitis from regression analyses. AUC (95\% Cl) of predicted probabilities; fever and nausea: 0.76 (95\% Cl, 0.65-0.87); fever, nausea and ESR < $17 \mathrm{~mm} / \mathrm{hr}$ : 0.85 (95\% Cl, 0.76-0.94). When including the finding of CSF WBC of 5- $100 \times 10^{6} / \mathrm{L}$ to the final model, an AUC of $0.9(95 \% \mathrm{Cl}, 0.0 .81-0.98)$ was reached

increased to 0.90 (95\% CI, 0.81-0.98) (Fig. 2). The respective OR for the variables in the latter model were 6.3 for fever (95\% CI 1.3-31), 10.9 for nausea (95\% CI, 1.7-70), 6.7 for ESR $<17 \mathrm{~mm} / \mathrm{hr}(95 \% \mathrm{CI}, 1.3-35)$ and 8.9 for CSF WBC $5-100 \times 10^{6} / \mathrm{L}(95 \%$ CI, $1.9-43)$.

\section{Discussion}

Encephalitis is a serious condition with a high morbidity, and symptoms may be difficult to interpret. The diagnostic approach toward this disorder needs to be highly sensitive. In this observational study we demonstrate a wide range of differential diagnoses to encephalitis, including conditions warranting immediate treatment and follow up. Of all patients with encephalopathy only $19 \%$ were diagnosed with encephalitis, and of these $48 \%$ had no agent identified despite intensive diagnostic workup. We found that the combination of fever together with low ESR and nausea was the best predictor in discriminating encephalitis from other causes of encephalopathy: These symptoms combined were present in $47 \%(7 / 15)$ of patients with encephalitis, whereas only $6 \%(4 / 71)$ of the patients in the encephalopathy group had the same combination. Although the combination shows potential for predictive ability, it can neither exclude nor confirm encephalitis before LP. Nevertheless, the model makes use of easily accessible symptoms and blood findings that could be useful as a practical screening tool when considering lumbar puncture in an encephalopathic population.

Treatable causes of encephalitis were identified in more than half of the cases. The most notable finding was the high proportion of non-viral causes of encephalitis. Other studies report similar findings $[4,6,15]$. The study was carried out in a hospital with primarily local function, and only two of the patients were transferred from other hospitals. Surprisingly, HSV1, the main reason for empirical treatment of encephalitis with acyclovir, was detected in only one patient during the study period. Our findings indicate a broad spectrum of identified causes, and support the emphasis on targeted testing depending on previous exposure or travel history, as suggested by international guidelines [23, 24]. Furthermore, national and local surveillance of etiology of encephalitis should be stressed as etiology may change over time.

Considering the diversity in symptomatology, differential diagnoses and etiology of encephalitis, clinicians face a challenging task in identifying these patients. Optimal evaluation and treatment of patients with encephalitis depend on early recognition, and although patients with encephalitis may have no pleocytosis in their CSF [2527], an LP should be performed without delay. Performing a LP is considered to be safe, as long as certain precautions are taken [28]. Our experience is that while the decision to perform a LP is straightforward if ABM is suspected, there is both delay and hesitation towards performing a LP for patients presenting with symptoms other than meningism. Lack of fever, no systemic sign of inflammation and other diagnosis being more probable, are arguments used against performing a LP. In this study we wanted to explore whether patients with encephalitis can be identified based on early clinical characteristics. Compared to patients presenting with encephalopathy of other causes, personality change, fever, focal findings, nausea and recent travel history 
were significantly more present in patients with encephalitis, but none of these findings alone did achieve a diagnostic accuracy of more than $70 \%$. On the other hand, despite four patients with non-viral cause of encephalitis, the median levels of inflammation markers like ESR, leucocytes, neutrophils, CRP and D-dimer were significantly lower in patients with encephalitis. Thus, inflammatory blood parameters below reference level in patients with encephalopathy should by no means be used as an argument to abandon a LP. This finding is in accordance with a recently published study of Gennai et al., where a normal C-reactive protein in the absence of past neurological history together with normal/high blood pressure and seizure was proposed as a scoring tool for HSV encephalitis [29]. The association between fever and encephalitis in our study is not surprising as fever is integrated in the case definition, however five $(25 \%)$ of the patients presented without fever. In four of these patients, etiology was confirmed (1 NMDAr, 2 with VZV, 1 with B. burgdorferi). Only one of these patients was immunosuppressed. Prediction models for encephalitis, similar to those proposed for bacterial meningitis, require larger studies [30-32]. Specific biomarkers for encephalitis would be very helpful in order to make a prompt diagnosis and initiate treatment. A search for biomarkers should be encouraged.

The identification of cause in $53 \%$ of our patients is an improvement compared to a retrospective study from the same hospital [21]. Increased focus on encephalitis, better diagnostic tools and/or more appropriate sampling on admission may be explanations for this. However, other studies have reported higher proportion of patients with known etiology $(63-70 \%)[5,6]$.

The major strength of the present study is the clinically relevant and well-characterized control group based on our wide inclusion criteria in a daily life clinical setting, all considered to have some degree of encephalopathy. Recognition of the encephalitic patient, no matter cause, is mandatory for optimal evaluation as many patients with both infectious as well as immune mediated encephalitis benefit from early treatment. Therefore, we consider the heterogeneity in the causes of encephalitis observed in this study to be an advantage.

Clinical studies of rare conditions require large study populations, and the statistical power of the present study is relatively low due to the low number of cases with encephalitis, this implies that the validity of our findings may be limited. Furthermore, the confidence intervals are wide for some parameters. The case definition used in this study was based on a consortium definition which, due to clinical overlap, was formulated to capture both encephalopathy of presumed infectious etiology and encephalitis [22]. Patients having other conditions that could explain the state of encephalopathy, patients with encephalopathy $<24$ hours and patients in whom less than two minor criteria were fulfilled were strictly categorized "encephalopathy of other cause" (group B), including those with bacterial and aseptic meningitis [33]. Thus, some patients with encephalitis may have been misclassified.

\section{Conclusion}

We found that the combination of nausea and fever together with a low level of ESR increased the probability of having encephalitis in an encephalopathic population. Normal inflammatory blood parameters and lack of fever cannot be used to defer or abandon LP. A wide diversity of etiological agents was found, and earlier studies showing herpes simplex as the most common cause of encephalitis was not confirmed in our material. We demonstrated a wide variety in differential diagnoses of encephalitis, many of which warrant immediate treatment. Larger clinical studies are needed to validate screening tools for encephalitis, and possible biomarkers need to be explored.

\section{Additional files}

Additional file 1: Diagnostic evaluation of patients with suspected encephalitis (PDF $184 \mathrm{~kb}$ )

Additional file 2: ROC curves of relevant parameters showing AUC for predicting encephalitis in an encephalopathic population; Legend (in figure): AUC of probability of encephalitis for individual symptoms and findings, data from univariate logistic regression analyses. Figure 2a: personality change: $0.62(95 \% \mathrm{Cl}, 0.47-0.76)$, focal findings: $0.63(95 \% \mathrm{Cl}$, 0.49-0.78), fever: 0.63 (95\% Cl, 0.50-0.76), travel: 0.64 (95\% Cl, 0.49-0.79), nausea: 0.69 (95\% Cl, 0.56-0.82). Figure $2 \mathrm{~b}: \mathrm{ESR}<17 \mathrm{~mm} / \mathrm{hr}: 0.66(95 \% \mathrm{Cl}$, $0.52-0.79)$, blood leucocytes < $10 \times 10^{9} / \mathrm{L}: 0.63$ (95\% Cl, 0.50-0.76), blood neutrophils < $7.3 \times 10^{9} / \mathrm{L}$ : $0.64(95 \% \mathrm{Cl}, 0.51-0.78)$. Figure 2C: CSF WBC 5$100 \times 10^{6} / \mathrm{L}: 0,70(95 \% \mathrm{Cl}, 0,57-0,84)$, CSF protein > 0,45 g/L: 0,71 $(95 \% \mathrm{Cl}$, 0.59-0.83). (PDF $121 \mathrm{~kb}$ )

\section{Abbreviations}

ABM: Acute bacterial meningitis; ADV: Adenovirus; AUC: Area under the curve; CNS: Central nervous system; CT: Computed tomography; DM: Diabetes mellitus; EEG: Electroencephalogram; ESR: Erythrocyte sedimentation rate; GCS: Glasgow coma scale; HSV1: Herpes simplex 1 virus; ICU: Intensive care unit; LP: Lumbar puncture; MRI: Magnetic resonance imaging; NMDA: N-methyl-D-aspartate; PCR: Polymerase chain reaction; ROC: Receiver operating characteristics; TB: Mycobacterium tuberculosis; VZV: Varicella zoster virus; WBC: White blood cell count

\section{Acknowledgements}

The Department of Infectious Diseases at Ullevaal Hospital represented by head of department professor Dag Kvale (MD, PhD) and associate professor Anne Ma Dyrhol Riise (Head of R\&D, MD, PhD) provided salary and office facilities to EQP during the study period. The authors are especially grateful to nurses and physicians at the Emergency Room, the Medical Intensive Care Unit, the Department of Internal Medicine and the Department of Neurology at Oslo University Hospital, Ullevaal for their enthusiastic and friendly help in including patients during the study period. We would also like to thank laboratory staff at the Department of Microbiology for excellent service. Finally, we thank the patients and next of kin who gave consent to participate in this study. 


\section{Availability of data and materials}

The dataset used during the current study is stored in a research server at Oslo University Hospital. An anonymized version can be made available from the corresponding author on reasonable request.

\section{Authors' contributions}

Study design: VO, EQP, OD, AMBK. All included patients were evaluated and interviewed by the primary investigator (EQP) during the first two days of hospitalization. All patients categorized as encephalitis were discussed and evaluated within the research group (VO, AMBK, OD). KE evaluated the presence of focal neurologic findings. EL reviewed the MRI findings of patients with encephalitis. Data analysis and statistical analyses: LS, EQP. All authors contributed to revision of the manuscript and approved the final version.

\section{Ethics approval and consent to participate}

The Regional Committees for Medical and Health Research Ethics (REC South East, reference number 2011/2578) and the ethical council of the hospital reviewed and approved the study protocol. Written informed consent was obtained from all individual patients or their next of kin included in the study.

\section{Consent for publication}

Not applicable.

\section{Competing interests}

The authors declare that they have no competing interests.

\section{Publisher's Note}

Springer Nature remains neutral with regard to jurisdictional claims in published maps and institutional affiliations.

\section{Author details}

'Department of Infectious Diseases, Oslo University Hospital Ullevaal, P. O. Box 4956, Nydalen, N-0450 Oslo, Norway. ${ }^{2}$ Institute of Clinical Medicine, University of Oslo, P.O Box 1171, Blindern, 0318 Oslo, Norway. ${ }^{3}$ Department of Microbiology, Oslo University Hospital, P.O. Box 4956, Nydalen, N0450 Oslo, Norway. ${ }^{4}$ Faculty of Medicine, University of Oslo, P.O Box 1078, Blindern, 0316 Oslo, Norway. ${ }^{5}$ Department of Radiology and Nuclear Medicine, Oslo University Hospital, Rikshospitalet, Sognsvannsveien 20, N-0372 Oslo, Norway. ${ }^{6}$ Sorlandet Hospital Arendal, Sykehusveien 1, N-4809 Arendal, Norway. ${ }^{7}$ Department of Neurology, Oslo University Hospital, Ullevaal Hospital, P.O. Box 4956, N-0450 Oslo, Norway. ${ }^{8}$ Oslo Group of Biostatistics and Epidemiology Oslo University Hospital, P.O. Box 4950, Sogn Arena, N-0424 Oslo, Norway. ${ }^{9}$ Department of Acute Medicine, Oslo University Hospital, Ullevaal Hospital, P. O. Box 4956, Nydalen, N-0450 Oslo, Norway.

\section{Received: 21 December 2017 Accepted: 29 November 2018} Published online: 22 January 2019

\section{References}

1. Whitley RJ, Cobbs CG, Alford CA Jr, Soong SJ, Hirsch MS, Connor JD, Corey L, Hanley DF, Levin M, Powell DA. Diseases that mimic herpes simplex encephalitis. Diagnosis, presentation, and outcome. NIAD collaborative antiviral study group. Jama. 1989;262(2):234-9.

2. Bradshaw MJ, Venkatesan A. Herpes simplex Virus-1 encephalitis in adults: pathophysiology, diagnosis, and management. Neurotherapeutics. 2016; 13(3):493-508.

3. Glaser CA, Gilliam S, Schnurr D, Forghani B, Honarmand S, Khetsuriani N, Fischer M, Cossen CK, Anderson LJ. In search of encephalitis etiologies: diagnostic challenges in the California encephalitis project, 1998-2000. Clin Infect Dis. 2003;36(6):731-42.

4. Mailles A, Stahl JP. Infectious encephalitis in France in 2007: a national prospective study. Clin Infect Dis. 2009;49(12):1838-47.

5. Singh TD, Fugate JE, Rabinstein AA. The spectrum of acute encephalitis: causes, management, and predictors of outcome. Neurology. 2015;84(4): 359-66.

6. Granerod J, Ambrose HE, Davies NW, Clewley JP, Walsh AL, Morgan D, Cunningham R, Zuckerman M, Mutton KJ, Solomon T, et al. Causes of encephalitis and differences in their clinical presentations in England: a multicentre, population-based prospective study. Lancet Infect Dis. 2010; 10(12):835-44.

7. Popiel M, Perlejewski K, Bednarska A, Dzieciatkowski T, Paciorek M, Lipowski D, Jablonowska M, Czeszko-Paprocka H, Bukowska-Osko I, Caraballo Cortes $\mathrm{K}$, et al. Viral etiologies in adult patients with encephalitis in Poland: a prospective single center study. PLoS One. 2017;12(6):e0178481.

8. Whitley RJ, Alford CA, Hirsch MS, Schooley RT, Luby JP, Aoki FY, Hanley D, Nahmias AJ, Soong SJ. Vidarabine versus acyclovir therapy in herpes simplex encephalitis. N Engl J Med. 1986;314(3):144-9.

9. Skoldenberg B, Forsgren M, Alestig K, Bergstrom T, Burman L, Dahlqvist E, Forkman A, Fryden A, Lovgren K, Norlin K, et al. Acyclovir versus vidarabine in herpes simplex encephalitis. Randomised multicentre study in consecutive Swedish patients. Lancet. 1984;2(8405):707-11.

10. Utley TF, Ogden JA, Gibb A, McGrath N, Anderson NE. The long-term neuropsychological outcome of herpes simplex encephalitis in a series of unselected survivors. Neuropsychiatry Neuropsychol Behav Neurol. 1997; 10(3):180-9.

11. Raschilas F, Wolff M, Delatour F, Chaffaut C, De Broucker T, Chevret S, Lebon $P$, Canton P, Rozenberg F. Outcome of and prognostic factors for herpes simplex encephalitis in adult patients: results of a multicenter study. Clin Infect Dis. 2002;35(3):254-60.

12. Kaewpoowat Q, Salazar L, Aguilera E, Wootton SH, Hasbun R. Herpes simplex and varicella zoster CNS infections: clinical presentations, treatments and outcomes. Infection. 2016;44(3):337-45.

13. Glaser CA, Honarmand S, Anderson LJ, Schnurr DP, Forghani B, Cossen CK, Schuster FL, Christie LJ, Tureen JH. Beyond viruses: clinical profiles and etiologies associated with encephalitis. Clin Infect Dis. 2006;43(12):1565-77.

14. Granerod J, Cunningham R, Zuckerman M, Mutton K, Davies NW, Walsh AL, Ward KN, Hilton DA, Ambrose HE, Clewley JP, et al. Causality in acute encephalitis: defining aetiologies. Epidemiol Infect. 2010;138(6):783-800.

15. Sonneville R, Gault N, de Montmollin E, Klein IF, Mariotte E, Chemam S, Tubach F, Mourvillier B, Timsit JF, Wolff M et al: Clinical spectrum and outcomes of patients with encephalitis requiring intensive care. Eur J Neurol. 2015, 22(1):6-16.

16. Mailles A, De Broucker T, Costanzo P, Martinez-Almoyna L, Vaillant V, Stahl JP. Long-term outcome of patients presenting with acute infectious encephalitis of various causes in France. Clin Infect Dis. 2012;54(10):1455-64.

17. Titulaer MJ, McCracken L, Gabilondo I, Armangue T, Glaser C, lizuka T, Honig LS, Benseler SM, Kawachi I, Martinez-Hernandez E, et al. Treatment and prognostic factors for long-term outcome in patients with anti-NMDA receptor encephalitis: an observational cohort study. Lancet Neurol. 2013; 12(2):157-65.

18. Granerod J, Tam CC, Crowcroft NS, Davies NW, Borchert M, Thomas SL. Challenge of the unknown. A systematic review of acute encephalitis in non-outbreak situations. Neurology. 2010;75(10):924-32.

19. George BP, Schneider EB, Venkatesan A. Encephalitis hospitalization rates and inpatient mortality in the United States, 2000-2010. PLoS One. 2014;9(9):e104169.

20. Calleri G, Libanore V, Corcione S, De Rosa FG, Caramello P. A retrospective study of viral central nervous system infections: relationship amongst aetiology, clinical course and outcome. Infection. 2017;45(2):227-31.

21. Quist-Paulsen E, Kran AM, Dunlop O, Wilson J, Ormaasen V. Infectious encephalitis: a description of a Norwegian cohort. Scand J Infect Dis. 2013; 45(3):179-85.

22. Venkatesan A, Tunkel AR, Bloch KC, Lauring AS, Sejvar J, Bitnun A, Stahl J-P, Mailles A, Drebot M, Rupprecht CE, et al. Case definitions, diagnostic algorithms, and priorities in encephalitis: consensus statement of the international encephalitis consortium. Clin Infect Dis. 2013;57(8):1114-28.

23. Solomon T, Michael BD, Smith PE, Sanderson F, Davies NW, Hart IJ, Holland M, Easton A, Buckley C, Kneen R, et al. Management of suspected viral encephalitis in adults--Association of British Neurologists and British Infection Association National Guidelines. J Infect. 2012;64(4):347-73.

24. Tunkel AR, Glaser CA, Bloch KC, Sejvar JJ, Marra CM, Roos KL, Hartman BJ, Kaplan SL, Scheld WM, Whitley RJ. The management of encephalitis: clinical practice guidelines by the Infectious Diseases Society of America. Clin Infect Dis. 2008;47(3):303-27.

25. Jakob NJ, Lenhard T, Schnitzler P, Rohde S, Ringleb PA, Steiner T, Wildemann B. Herpes simplex virus encephalitis despite normal cell count in the cerebrospinal fluid. Crit Care Med. 2012;40(4):1304-8.

26. Mook-Kanamori B, van de Beek D, Wijdicks EF. Herpes simplex encephalitis with normal initial cerebrospinal fluid examination. J Am Geriatr Soc. 2009; 57(8):1514-5. 
27. Fodor PA, Levin MJ, Weinberg A, Sandberg E, Sylman J, Tyler KL. Atypical herpes simplex virus encephalitis diagnosed by PCR amplification of viral DNA from CSF. Neurology. 1998;51(2):554-9.

28. Glimaker M, Sjolin J, Akesson S, Naucler P. Lumbar puncture performed promptly or after neuroimaging in adult bacterial meningitis: a prospective national cohort study evaluating different guidelines. Clin Infect Dis. 2017; 66(3):321-8

29. Gennai S, Rallo A, Keil D, Seigneurin A, Germi R, Epaulard O. Elaboration of a clinical and paraclinical score to estimate the probability of herpes simplex virus encephalitis in patients with febrile, acute neurologic impairment. Eur J Clin Microbiol Infect Dis. 2016;35(6):935-9.

30. Ray P, Badarou-Acossi G, Viallon A, Boutoille D, Arthaud M, Trystram D, Riou B. Accuracy of the cerebrospinal fluid results to differentiate bacterial from non bacterial meningitis, in case of negative gram-stained smear. Am J Emerg Med. 2007;25(2):179-84

31. Spanos A, Harrell FE Jr, Durack DT. Differential diagnosis of acute meningitis. An analysis of the predictive value of initial observations. Jama. 1989; 262(19):2700-7.

32. Hoen B, Viel JF, Paquot C, Gerard A, Canton P. Multivariate approach to differential diagnosis of acute meningitis. Eur J Clin Microbiol Infect Dis. 1995;14(4):267-74.

33. Bloch KC, Bitnun A, Glaser CA, Mailles A, Stahl JP, Tunkel AR, Venkatesan A. Reply to Jackson. Clin Infect Dis. 2015;61(2):293-4.

Ready to submit your research? Choose BMC and benefit from:

- fast, convenient online submission

- thorough peer review by experienced researchers in your field

- rapid publication on acceptance

- support for research data, including large and complex data types

- gold Open Access which fosters wider collaboration and increased citations

- maximum visibility for your research: over $100 \mathrm{M}$ website views per year

At $\mathrm{BMC}$, research is always in progress.

Learn more biomedcentral.com/submissions 